\title{
SLAM-Associated Protein Expression Analysis
}

National Cancer Institute

\section{Source}

National Cancer Institute. SLAM-Associated Protein Expression Analysis. NCI Thesaurus.

Code C115218.

A laboratory test to determine the presence or absence of SH2 domain-containing protein 1A (SLAM-associated protein, SAP) expression. Loss of SAP expression is associated with X-linked lymphoproliferative syndrome 1. 